\title{
Spatial-temporal Distribution of Salt Marshes in Intertidal Zone of China during 1985-2019
}

\author{
Guangwei Chen ${ }^{1}$, Zhanjiang $\mathrm{Ye}^{1}$, Runjie Jin ${ }^{1}$, Junyu $\mathrm{He}^{1,2}$, Jiaping $\mathrm{Wu}^{1}$, Jiali Gu ${ }^{1, *}$
}

1.Ocean College, Zhejiang University, Zhoushan, 316021, China

2.Ocean Academy, Zhejiang University, Zhoushan, China

* Corresponding author: Jiali Gu, jialigu@zju.edu.cn, Ocean College, Zhejiang University, Zhoushan, Zhejiang, 316021, China

\begin{abstract}
Based on the cloud platform of Google Earth Engine (GEE), this study selected Landsat 5/8 and Sentinel-2 remote sensing images and used Support Vector Machine (SVM) classification method to classify the 35 years of intertidal salt marshes in China, and verified the classification results in combination with field survey. Finally, combining with various driving factors, the reasons and laws affecting the changes of salt marshes species and area were discussed and analyzed. The main results of the study are as follows: The main types of salt marshes plants in China include Phragmites australis, Spartina alterniflora, Suaeda salsa, Scirpus mariquete, Tamarix chinensis, Cyperus malaccensis and Sesuvium portulacastrum.
\end{abstract}

The results salt marshes classification indicated that 166999.32 ha in 1985, 172893.87 ha in $1990,174952.29$ ha in $1995,125567.51$ ha in $2000,93257.97$ ha in $2005,102539.04$ ha in $2010,96302.92$ ha in 2015 , and 115722.75 ha in 2019. The main driving factors of salt marsh change from 1985 to 2015 are reclamation, mudflat aquaculture, climate change, coastal zone erosion, invasion of alien species, and natural competition and succession among salt marshes species. The results can be used to quantitatively analyze the salt marshes carbon storage in space and time, and provide data support for the protection of salt marsh wetlands, the restoration of ecological functions and the implementation of "carbon neutral".

Keywords: Salt Marshes, Google Earth Engine, SVM, Distribution, China's coast 1. Introduction

Salt marshes are found in the transitional zone between terrestrial and marine environments which are inhabited by halophyte communities (Chapman and Chadwick, 1974), and they grow on a variety of substrates, ranging from silt and sand to loose cobbles, clay, and gravel (Zuo et al., 2012). They provide a range of ecosystem benefits, such as coastal resilience, denitrification, filtration of pollutants, nursey habitat, food supply, nutrient cycling, and carbon storage and sequestration (Chung, 2005). Despite such important benefits, salt marshes in southeast China have been declining due to land development, less sediment input, eutrophication, and sea level rise (Crosby et al., 2016; Watson et al., 2017; Wigand et al., 2014; Altieri, et al., 2012; Deegan, et al., 2012; Kirwan, et al., 2010; Kirwan, et al., 2008 Holdredge, et al., 2009; Saintilan, et al., 2014; Armitage, et al., 2015). The most common salt 
marshes are Spartina, Phragmites, Scirpus, and other speices, such as Suaeda, Cyperus and Thatch. However, some evidence has been reported that, as an exotic species, Spartina, may compete with native plants, threaten native ecosystems and coastal aquaculture, and cause declines in local biodiversity (Brusati and Grosholza, 2007; Callaway and Josselyn, 1992; Daehler et al., 1996; Chen et al., 2005; Rosso et al., 2006; Wang et al., 2006; He et al., 2007; Huang and Zhang, 2007; Li and Zhang, 2008). The invasion and control of Spartina has been become a hot topic and drawn attention from biologists and ecologists in China and abroad worldwide (Thomas and Reid, 2007). Information on its quantity and location of salt marshes is worthy of further study and of importance to both scientists and governmental managers. However, no data has been published to date on the distribution of salt marshes in China in during the period 1985-2019, despite national and international concerns.

China has long coastlines with many kinds of salt marshes distributed. Open ocean, rivers, land, atmosphere, sediments and biota interact in coastal and shelf seas, leading to substantial spatial and temporal heterogeneity in carbon flows (Chen et al., 2009). Significantly higher rates of new primary production occur in the continental margins than in the open oceans because of the higher supply of nutrients from cross-shelf break upwelling and riverine input, in addition to the rapid remineralization of organic matter due to benthic coupling and enhanced pelagic (Walsh et al., 1988, 1991; Mackenzieetal et al., 1998a, b; Wollast et al., 1998; Liu et al.,2000; Muller-Karger et al., 2005). The intertidal zone is an important coastal ecosystem, characterized by high productivity and biodiversity and providing habitat for migratory shorebirds worldwide (Brockmann and Stelzer, 2008; Galbraith et al., 2002). Tidal flats also provide critical coastal protection from extreme storm events, and are often a component of the coastal geomorphologic system around high value commercial asset sites such as ports, harbours and recreational areas (Bell et al., 2016; Healy et al., 2002). In recent years, the intertidal zone has been attracting more and more attention, due to its high ecological benefits and economic values. Some zones relatively unaffected by man have been protected as natural conservation areas (Mason et al. 2010).

Remote sensing (RS) technique has been widely used to provide a useful tool for mapping vegetation, and monitoring vegetation dynamics and biodiversity conservation on a large scale (Ayres et al., 2004; Zhang et al., 2004; Hinkle and Mitsch, 2005). Technical barriers to national scale RS have become greatly reduced in recent years with the availability of free, post-processed satellite and aerial imagery with national to global coverage. Moreover, an increasing number of studies have adopted object-based image analysis (OBIA) to identify Spartina (Wan et al., 2014; Ouyang et al., 2011; Yu et al., 2006), and the OBIA and Support Vector Machine (SVM) have been proven to be promising tools for mapping the invasion of Spartina (Wang et al., 2015). With unmanned airborne vehicle (UAV) technologies, it is possible to acquire very high resolution (VHR) images for verifying the species of salt marshes at the patch scale, and the availability of VHR orthophotography merged with UAV imagery provides an opportunity to verify the species of plant community at the landscape scale. The characteristics of quick flight deployments and feasible flight timing of UAV make it ideal in monitoring salt marshes change over the intertidal zone where periodically inundated vegetation has limited exposure period (Zhu et al., 2019).

Google Earth Engine (GEE) has enabled time series, analysis in freshwater wetland change analysis (Hird et al., 2017). The GEE platform consists of a petabyte catalog of satellite imagery and geospatial datasets and a massively parallel, distributed 
runtime engine (Google Earth Engine Team, 2017). Cloud computing and HighPower Computing are frequently employed in time series studies to quantify ecological processes, and land cover land use change (LCLUC) (Vogelmann et al., 2016; Fu et al.,2016; Pasquarella et al., 2016). GEE facilitates our ability to understand LCLUC at regional and global scales. The utilization of these methods in salt marshes landscapes can further clarify how and where these ecosystems are changing (Campbell et al., 2020). GEE is a cloud-based platform for planetary-scale environmental data analysis. It combines a multi-petabyte catalog of satellite imagery and geospatial datasets, Google's computational infrastructure optimized for parallel processing of geospatial data, Application Programming Interfaces (APIs) for JavaScript and Python, and a web-based integrated development environment for rapid prototyping and visualization of complex spatial analyses. GEE is designed so that users rarely have to worry about map projections when doing computing at large area, projection parameters are requested in the output projection. By default, GEE performs nearest neighbor $(\mathrm{NN})$ resampling during reprojection (Chen et al., 2017).

In mainland China, most of the previous studies of Spartina invasion and salt marshes change have focused on local regions, and thus failed to update the spatial distribution salt marshes of China in a timely manner, even though this information is critical for supporting land management, protecting important habitats of endangered species, and ensuring ecological security in response to global change. The resulting information deficiency has limited decision-making regarding the sustainable ecosystem management of coastal wetlands and the socioeconomic development of coastal cities (Liu et al., 2018). To address this deficiency, this study provided a new observation using Landsat, Sentinel-2 and UAV images and the integration of SVM and GEE platform. Specifically, this study mapped the up-to-date distribution of salt marshes at the national scale, and records the causes of temporal and spatial changes of salt marshes.

\section{Materials and Methods}

\subsection{Study Area}

Salt marshes are widely distributed in coastal China, thus the study area contains the whole coastal intertidal zone in China ranging from $18^{\circ} \mathrm{N}-41^{\circ} \mathrm{N}$ in latitude and $108^{\circ} \mathrm{E}-124^{\circ} \mathrm{E}$ in longitude, covering warm temperate zone, subtropical zone and tropical climatic zones. In this study, a $10-\mathrm{km}$ buffer zone along the coatline was generated to delineate the potential areas of salt marshes. A similar $25-\mathrm{km}$ buffer zone has been used to map mangrove forests along the Chinese coastline by Chen (Chen et al., 2017). The common salt marshes species in coastal China include Spartina alterniflora, Phragmites australis, Suaeda salsa, Tamarix chinensis, Scirpus mariquete, Cyperus malaccensis, Imperata cylindrica, Aeluropus littoralis and Sesuvium (Zuo et al., 2012), some of which are widely distributed but others only in low abudance. Phragmites australis, Suaeda salsa, Tamarix chinensis and Aeluropus litoralis are mainly distributed in Northern China such as the Liao River Delta and the Yellow River Delta. The invasive species Spartina is mainly distributed in the coastal areas of East China, including Jiangsu, Shanghai, Zhejiang and Fujian, and has also appeared scatterly in Liaoning, Hainan and Taiwan. At this point, Spartina has spread from the very north coast of Liaoning to the further south of Hainan, which should be taken seriously as invasive plant. It is evident that Spartina species had to adapt to very different climatic and geographic conditions along the Chinese coast after being introduced, resulting in differences in the development of this new vegetation in different areas (Zuo et al., 2012). Scirpus mariqueter is mainly distributed in 
Shanghai, Jiangsu and Hangzhou Bay. Cyperus malaccens is mainly distributed in South China regions such as Guangdong and Guangxi.

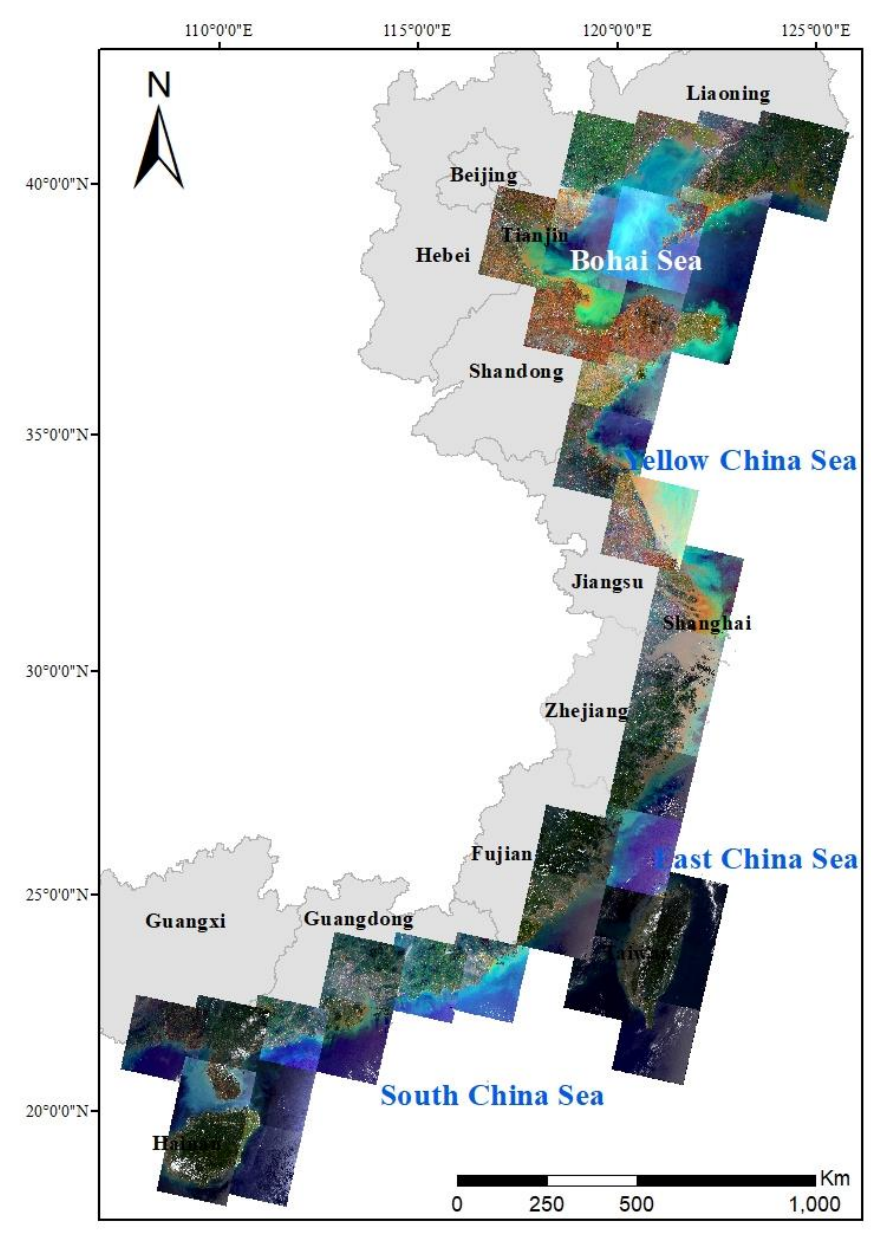

Figure 1 Location of the study area

\subsection{Data collection}

A large number of remote sensing images, such as the Sentinel and Landsat series, are publicly available and cover the study area in both time and space. In this study, we processed the Sentinel-2, Landsat Thematic Mapper (TM)/Operational Land Imager (OLI) images on GEE cloud computing platform to explore the spatiotemporal dynamics of salt marshes in intertidal zone during the period 1985-2019.

Multispectral Landsat 5, Landsat 8 panchromatic and Sentinel-2 have $30 \mathrm{~m}, 15 \mathrm{~m}$ and $10 \mathrm{~m}$ spatial resolution respectively. Multi-temporal images in specific locations were selected for the greatest separation of salt marshes from other species based on the phenological stages and tidal level. Generally, vegetation in the late growing season may show significant spectral difference. Therefore, images acquired in late summer and autumn are preferred for salt marshes identification in China. As tidal flooding reduces spectral reflectance and can add noise to the classification of salt marshes, images with low tides were preferred, in other words, the salt marshes located in lower intertidal zones could be easily identified (Mao et al., 2019). Thick cloud cover and heavy fog will reduce the quality of images. Thus, we selected images with less than $15 \%$ cloud cover or where the study area was not affected by cloud and fog. In some regions, all available images in certain year cannot meet the above critieria. 
Instead, we used images acquired in before or next a year.

2.3 Methods to identify salt marshes in intertidal zone

A support vector machine (SVM) is a machine learning technique based on the supervised machine learning model. An SVM is based on statistical learning theory and classifies data by determining a set of support vectors, which are members of the labeled training data samples. The main objective of an SVM is to find an optimal hyperplane for the classification of new data points (Mohammadi et al., 2021). The methods have been widely used to produce most of the land cover products. We conducted pre-processing and supervised classification of all images in the GEE platform. The SVM model were applied for classification, which was trained using randomly selected pixels of different land covers from the images. To better identify salt marshes spesices, two widely used vegetation indices (VIs) and four water-related spectral indices were applied in the SVM model: Nominalized Difference Vegetation Index (NDVI) (Tucker, 1979), Enhanced Vegetation Index (EVI) (Huete et al., 1997, 2002), Normalized Difference Water Index (NDWI) (S. K. McFEETERS, 1996), modified Normalized Difference Water Index (mNDWI) (Xu, 2006), Automated Water Extraction Index (AWEI) (Feyisa et al., 2014), and AWEIsh for further improvement of accuracy by removing shadow pixels that AWEInsh may not effectively eliminate (Feyisa et al., 2014). In addition, Near Infrared band (NIR) and Short-wave Infrared 1 band (SWIR1) were also applied to help identification of salt marshes species.

$$
\begin{gathered}
N D V I=\frac{\rho_{\text {NIR }}-\rho_{\text {red }}}{\rho_{\text {NIR }}+\rho_{\text {red }}} \\
\text { EVI }=2.5 \times \frac{\rho_{\text {IIR }}-\rho_{\text {red }}}{\rho_{\text {NIR }}+6 \times \rho_{\text {red }}-7.5 \times \rho_{\text {blue }}+1} \\
N D W I=\frac{\rho_{\text {green }}-\rho_{\text {NIR }}}{\rho_{\text {green }}+\rho_{\text {NIR }}} \\
m N D W I=\frac{\rho_{\text {green }}-\rho_{\text {SWIR }}}{\rho_{\text {green }}+\rho_{\text {SWIR }}} \\
\text { AEWIsh }=\rho_{\text {blue }}+2.5 \times \rho_{\text {green }}-1.5 \times\left(\rho_{\text {NIR }}-\rho_{\text {SWIR } 2}\right)-0.25 \times \rho_{\text {SWIR } 2}
\end{gathered}
$$

where $\rho_{\text {blue }}, \rho_{\text {green }}, \rho_{\text {red }}, \rho_{\text {NIR }}, \rho_{S W I R}$ and $\rho_{S W I R 2}$ are blue $(\mathrm{B} 1: 450-520 \mathrm{~nm})$, green $(B 2: 520-600 \mathrm{~nm})$, red (B3:630-690 nm), near-infrared (NIR,B4:760-900 nm), shortwave infrared 1 (SWIR, B5:1550-1750 nm) and shortwave infrared 2 (SWIR2, B7:2090-2350 nm) bands of Landsat TM/OLI imagery, respectively.

Field survey and photos taken by UAV helped to modify the obvious misclassification and missing points of initial GEE classification results, which were conducted in ArcGIS 10.7 (ESRI 2019) by visual interpretation. For some regions, such as Hainan, Macao, Hong Kong and Taiwan, salt marshes distributions were too limited to be effectively identified and extracted from remote sensing images.

Therefore, high-resolution images from Google earth were used to visually interpret and manually extract salt marshes distribution information based on knowledge and experience. Due to the limited researches about salt marshes in Hong Kong, Macau, and Taiwan, we also used Google Street View to assist the identification of salt marshes species in small areas. The flow chart of salt marshes classification was shown in Figure 2. 


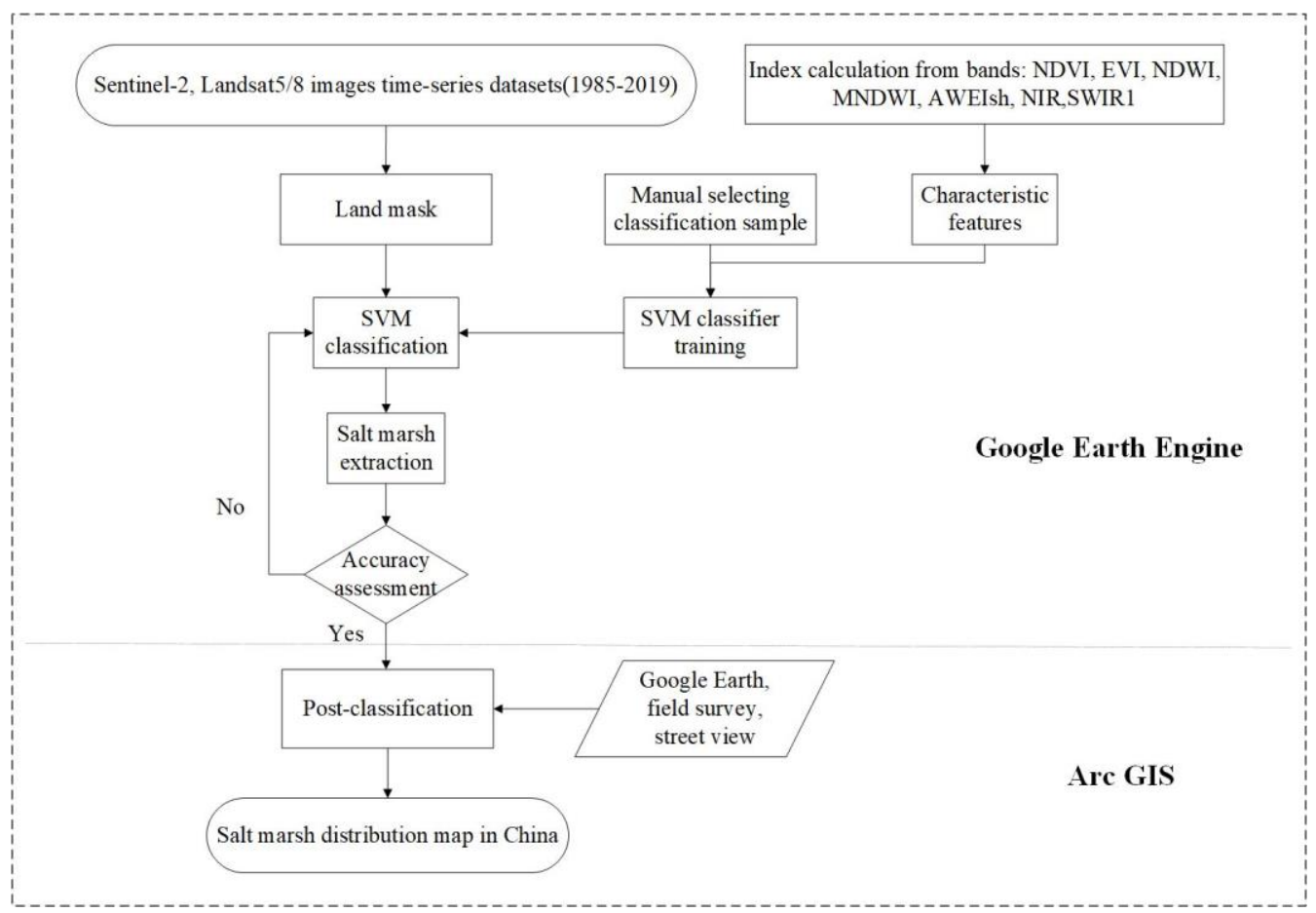

Figure 2 The flow chart of salt marshes classification

\subsection{On-site investigation}

On-site investigation were carried out using the hand-held Geographic Positioning System (GPS), digital camera and UAV in a vehicle traveling for recording the ecological conditions at field from Liaoning, Shandong, Jiangsu, Shanghai, Zhejiang, Fujian, Guangdong, Hainan and Guangxi during July, October and November, 2019. UAV was used to examine the plant patches far away from the road and coastal dam (Mao et al., 2019). The aerial photo data (R,G,B) was gathered by a Hasselblad L1D20c of Dji Mavic -2 pro and a multispectral camera array with 5 cameras covering Blue, Green, Red, Red Edge, and Near Infrared bands of Dji P4 Multispectral. Salt marshes species identification, sampling, and interviews focusing on the pros and cons introduction were also conducted during the on-site survey.

\section{Classification accuracy}

The accuracy of salt marshes classification results was evaluated based on the field survey data in 2019. Categorization thresholds were applied to salt marshes identification in all satellite images. We surveyed 51 locations during July, October and November, 2019 to collect salt marshes information in China. The validation accuracy ranged from $88.6 \%$ to $96.9 \%$ in different regions with an average of $93.3 \%$. The validation Kappa index ranged from 0.86 to 0.96 with an average of 0.91 (Table 1). These estimation index indicated overall satisfactory classification results. 
Table 1 Overall accuracy (OA) and Kappa index of SVM classifier and validation

\begin{tabular}{lllll}
\hline \multirow{2}{*}{ Region } & \multicolumn{2}{l}{ SVM classifier } & \multicolumn{2}{l}{ Validation } \\
& OA $(\%)$ & Kappa & OA $(\%)$ & Kappa \\
\hline Liaoning & 91.4 & 0.88 & 96.1 & 0.95 \\
Hebei \& Tianjin & 97.8 & 0.97 & 96.3 & 0.94 \\
Shandong & 91.1 & 0.89 & 88.6 & 0.86 \\
Jiangsu & 97.1 & 0.96 & 93.7 & 0.92 \\
Shanghai & 89.3 & 0.87 & 88.7 & 0.86 \\
Zhejiang & 94.3 & 0.93 & 95.2 & 0.94 \\
Fujian & 93.7 & 0.92 & 96.9 & 0.96 \\
Guangdong & 87.4 & 0.83 & 93.3 & 0.91 \\
Guangxi & 92.3 & 0.91 & 90.9 & 0.89 \\
Average & 92.7 & 0.91 & 93.3 & 0.91 \\
\hline
\end{tabular}

In order to show the accuracy of classification results more intuitively, we selected the Liao River Estuary as an example (Figure 3), and compared the classification results with the aerial photos of UAV in field survey, to prove that the classification results of salt marshes vegetation were satisifactory.

As shown in Figure 3, the verification site is located near the Liao River Estuary in Panjin City, Liaoning Province, and the red triangle represents the point location of UAV aerial shot.Taking the three verification points V1-V3 in the classification result diagram and UAV aerial image as an example,V1 is the Suaeda salsa area, V2 is the transition area between Suaeda salsa and Phragmites, and V3 is Phragmites area. The classification results are consistent with UAV aerial images, which directly proves the correctness of salt marshes vegetation classification.
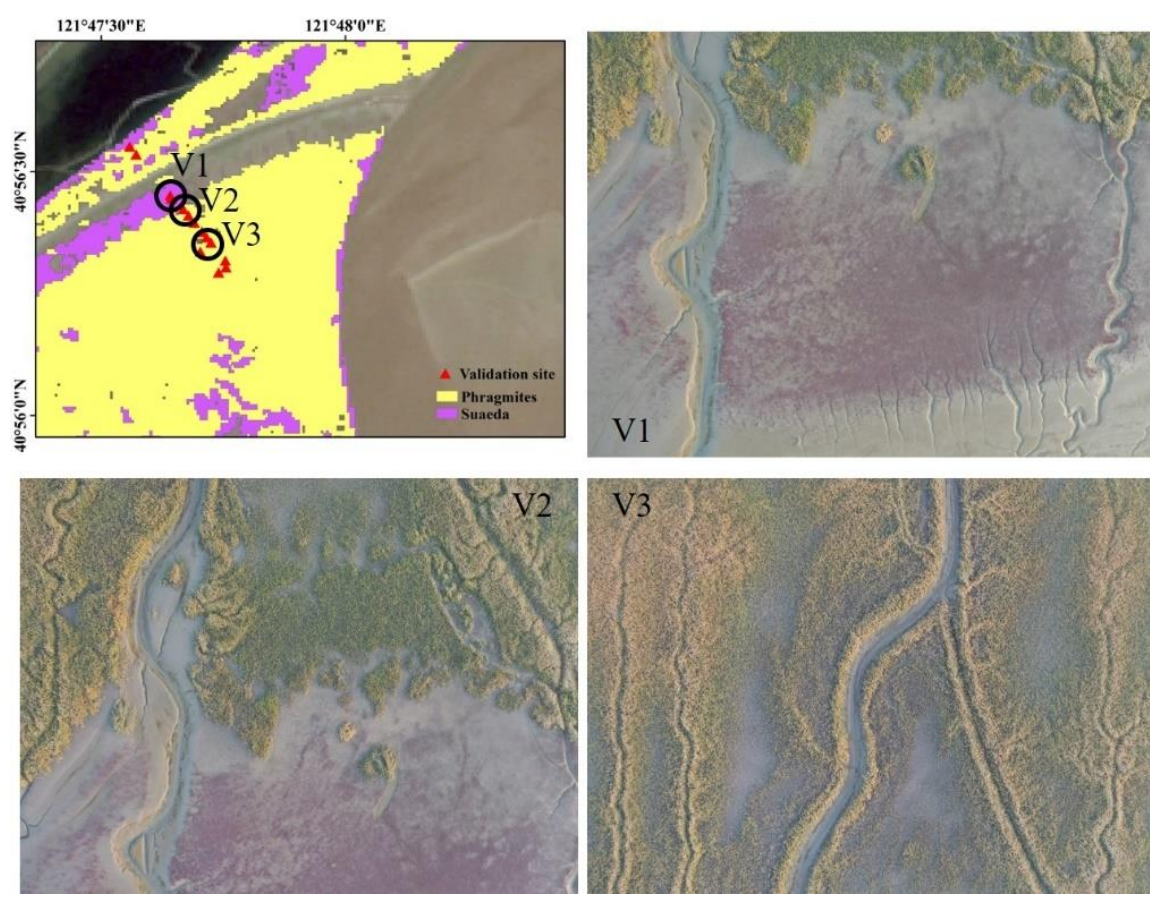

Figure 3 Salt marshes classification result and aerial photos validation by drones in 
Liao river estuary (V1-V3: aerial photos by drones, the purple areas represent Suaeda and the yellow-green areas represent Phragmites)

4 Results

4.1 Total area of salt marshes and spatial distribution during 1985-2019

The results of salt marshes vegetation in different coastal provinces along the China's intertidal zone in 1985-2019 is summarized in Table 1.

Table 1 Salt marshes species and areal extents along coastal China in 1985 - 2019 (Unit: ha)

\begin{tabular}{|c|c|c|c|c|c|c|c|c|c|}
\hline Regions & Species & 1985 & 1990 & 1995 & 2000 & 2005 & 2010 & 2015 & 2019 \\
\hline \multirow{3}{*}{ Liaoning } & Spartina & - & - & - & - & - & - & - & 33.01 \\
\hline & Phragmites & 7918.48 & 6952.40 & 5905.07 & 4296.90 & 3762.88 & 4944.79 & 3474.30 & 3716.90 \\
\hline & Suaeda & 4975.87 & 3159.03 & 2811.92 & 2744.42 & 1191.48 & 2419.03 & 2160.86 & 1430.67 \\
\hline \multirow{3}{*}{$\begin{array}{c}\text { Hebei\& } \\
\text { Tianjin }\end{array}$} & Spartina & - & - & 1.61 & 81.29 & 64.75 & 236.56 & 488.75 & 429.62 \\
\hline & Phragmites & 856.52 & 568.83 & 194.55 & 545.08 & 127.95 & 236.44 & 90.61 & 204.48 \\
\hline & Suaeda & 230.95 & 109.98 & 75.89 & 110.46 & 101.12 & 17.31 & 10.11 & 27.37 \\
\hline \multirow{3}{*}{ Shandong } & Spartina & - & 128.38 & 236.43 & 1044.90 & 763.44 & 1093.96 & 3418.22 & 6980.76 \\
\hline & $\begin{array}{c}\text { Phragmite(in } \\
\text { cluding:Tam } \\
\text { arisk) }\end{array}$ & 43941.79 & 18642.70 & 11291.24 & 11428.06 & 10874.74 & 10829.42 & 7620.99 & 8107.93 \\
\hline & Suaeda & 38170.57 & 60881.06 & 59700.54 & 21382.73 & 9118.56 & 9706.49 & 5087.56 & 1591.23 \\
\hline \multirow{3}{*}{ Jiangsu } & Spartina & 2.93 & 875.47 & 8081.70 & 12011.29 & 10561.73 & 13868.50 & 9938.33 & 16919.20 \\
\hline & $\begin{array}{l}\text { Phragmites } \\
\text { (including: } A \\
\text { eluropus) }\end{array}$ & 6173.65 & 21954.86 & 24862.91 & 17496.22 & 3900.70 & 4887.32 & 9435.45 & 7644.89 \\
\hline & Suaeda & 37459.14 & 26630.92 & 25322.75 & 11167.03 & 12766.17 & 10068.29 & 1523.02 & 461.40 \\
\hline \multirow{3}{*}{ Shanghai } & Spartina & - & - & 31.58 & 95.28 & 2199.19 & 1815.13 & 8324.91 & 16227.50 \\
\hline & Phragmites & 9127.08 & 9222.05 & 13215.45 & 10246.22 & 6756.41 & 7901.08 & 9619.46 & 11371.50 \\
\hline & Scirpus & 9145.20 & 7798.01 & 6554.63 & 8515.13 & 3176.41 & 4656.47 & 7096.45 & 6485.92 \\
\hline \multirow{3}{*}{ Zhejiang } & Spartina & 480.17 & 343.81 & 4462.28 & 7489.41 & 8314.77 & 11478.72 & 10175.21 & 14877.20 \\
\hline & Phragmites & 406.44 & 712.35 & 1115.87 & 987.23 & 1077.70 & 1247.98 & 107.73 & 1063.39 \\
\hline & Scirpus & 2007.12 & 4563.63 & 3807.59 & 6794.91 & 2360.72 & 2157.67 & 2304.78 & 3869.00 \\
\hline \multirow{3}{*}{ Fujian } & Spartina & 33.49 & 1126.42 & 4422.27 & 5043.93 & 7050.62 & 7509.37 & 10625.41 & 10217.20 \\
\hline & Phragmites & 46.10 & 263.25 & 353.29 & 583.66 & 194.59 & 135.83 & 112.70 & 144.70 \\
\hline & Scirpus & 1147.48 & 4890.76 & 6369.69 & 6592.10 & 6105.55 & 5702.41 & 1880.21 & 121.28 \\
\hline \multirow[b]{2}{*}{$\begin{array}{l}\text { Guangdo } \\
\text { ng } \\
\text { (including } \\
\text { : Hong } \\
\text { Kong and } \\
\text { Macau) }\end{array}$} & Spartina & 32.18 & 318.00 & 393.99 & 415.60 & 391.07 & 409.76 & 601.57 & 556.92 \\
\hline & $\begin{array}{c}\text { Phragmites(i } \\
\text { ncluding: } \\
\text { Cyperus) }\end{array}$ & 42.56 & 473.03 & 133.99 & 197.63 & 217.63 & 172.67 & 229.70 & 356.00 \\
\hline \multirow[b]{2}{*}{ Guangxi } & Spartina & 48.64 & 63.22 & 81.13 & 165.83 & 391.49 & 407.43 & 1957.61 & 1204.91 \\
\hline & $\begin{array}{c}\text { Cyperus(incl } \\
\text { uding:Phr } \\
\text { agmites) }\end{array}$ & 3420.24 & 2120.08 & 2429.75 & 1761.91 & 1319.91 & 1052.31 & 1438.54 & 523.91 \\
\hline \multirow[b]{2}{*}{ Hainan } & Phragmites & - & - & - & - & - & - & 1.22 & 1.00 \\
\hline & $\begin{array}{c}\text { Sesuvium(inc } \\
\text { luding: } \\
\text { Spartina) }\end{array}$ & - & - & - & - & - & - & 202.67 & 226.11 \\
\hline \multirow{3}{*}{ Taiwan } & Spartina & - & - & - & - & - & - & 97.78 & 149.05 \\
\hline & Phragmites & - & - & - & - & - & - & 2.77 & 27.70 \\
\hline & Sesuvium & - & - & - & - & - & - & - & 86.64 \\
\hline
\end{tabular}


4.2 Distribution changes of salt marshes in China

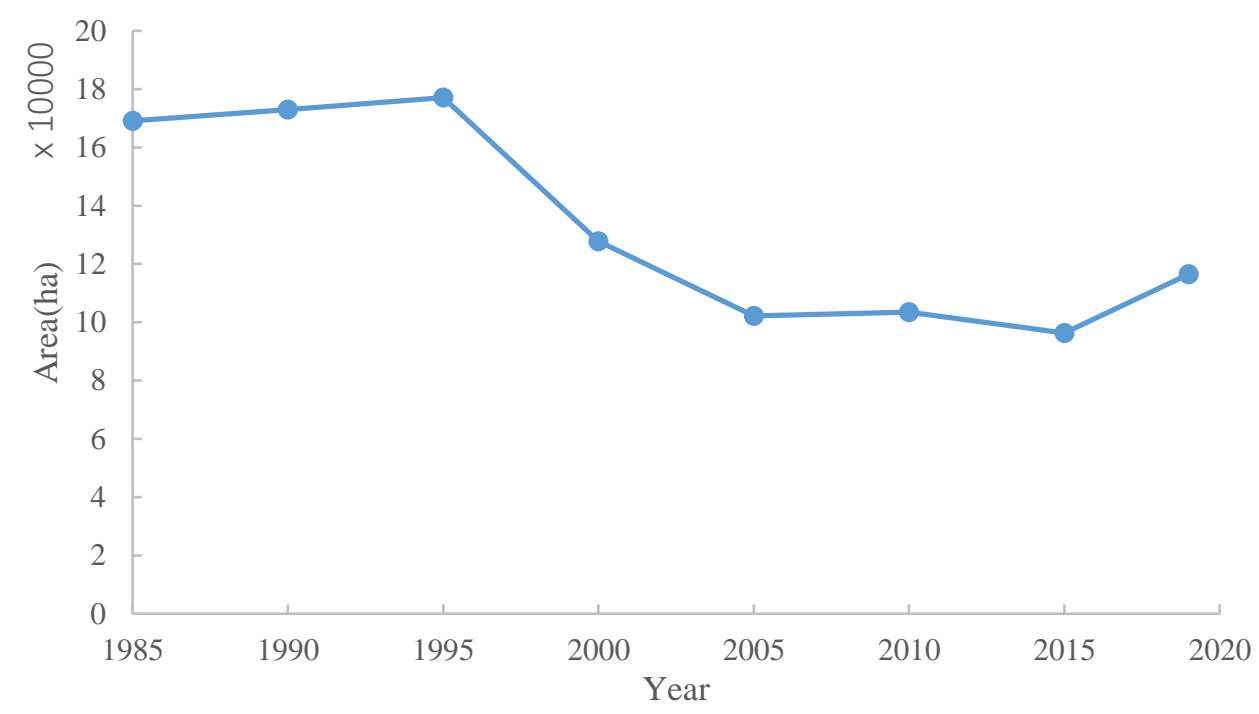

Figure 4 Temporal changes of salt marshes in intertidal zone of China

As can be seen from Figure 6, the total area of intertidal salt marshes in China increased slowly from 1985 to 1995 , and reached a maximum in 1995 (177254.71 ha). The area decreased from 1995 to 2005, and the area decreased by $27.40 \%$ from 1995 to 2000 . From 2005 to 2015 , the total area changed little and tended to be stable, and reached the lowest point $(98028.17 \mathrm{ha})$ in 2015 . The total area of salt marshes increased by $18.84 \%$ from 2015 to 2019 .

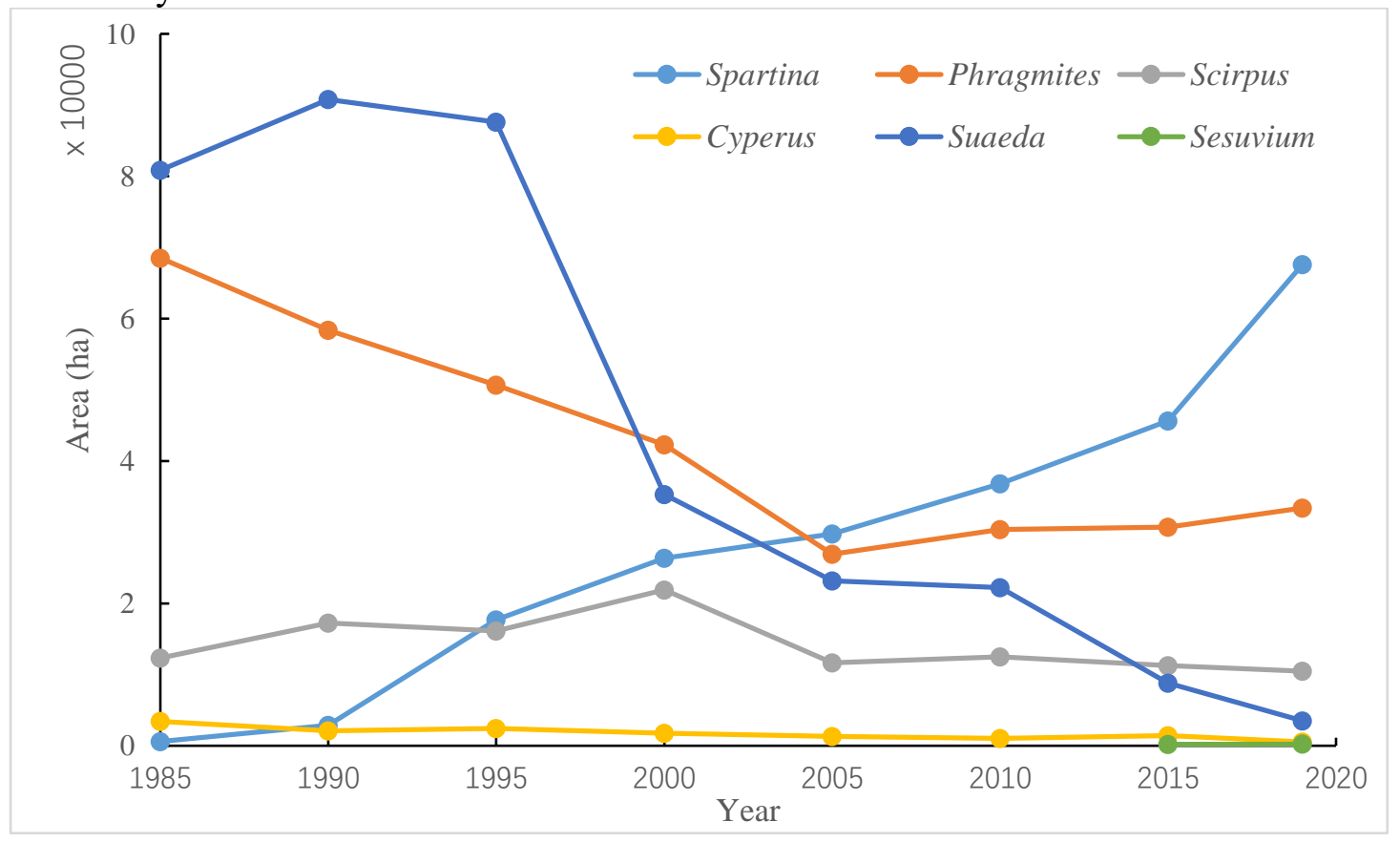

Figure 5 Temporal changes of multi salt marshes

As can be seen from Figure 7, in 1985, Suaeda had the largest area of salt marshes area in China, reaching 80836.52 ha, while Spartina only had 597.41 ha. By 1990, the 
area of Suaeda reached its peak (90781.00 ha), at which time the number of Scirpus also increased slightly, and the area of Phragmites decreased to 59356.00 ha. From 1990 to 1995, the area of Suaeda, Phragmites and Scirpus all showed a decreasing trend, while Spartina and Cyperu increased in varying degrees. From 1995 to 2000, the area of Suaeda decreased sharply, and the average annual area decreased by 10462.50 ha/a. Spartina and Scirpus showed a gradual increasing trend. But from 2000 to 2005, the total area of Spartina only showed a rising trend, and the changes of Phragmites, Scirpus, Suaeda, and Cyperus were all decreasing; the annual average area of Phragmites and Scirpus decreased the most, with 3071.17 ha /a and 2051.76 ha $/ \mathrm{a}$, and the areas of different species were the most similar at this time. The area of different kinds of salt marshes changed slowly from 2005 to 2010. In 2015, Suaeda had less area than Scirpus, with Spartina being the most abundant, Phragmites the second, and Sesuvium the least. From 2015 to 2019, Spartina, Phragmites, and Scirpus showed an increasing trend, while the area of Scirpus and Suaeda decreased. The annual average area of Spartina increased the most, reaching 4393.88 ha/a. Spartina has been on the rise since 1985, and the area of Spartina has ranked first among all salt marshes species since 2005. The area of Phragmites decreased continuously from 1985 to 2005, and reached the lowest point (26912.61 ha) in 2005, and leveled off after 2005. The area of Suaeda increased only from 1985 to 1990, and then decreased, and reached the lowest point in 2019, which was 3510.66 ha. The area of Scirpus had little change in general. It reached the highest point in 2000, decreased slightly from 2000 to 2005, and then leveled off. the area of Suaeda showed a decreasing trend from 1985 to 2019, and reached the highest point in 1985 with 3420.24 ha. The area will reach a minimum of 542.84 ha in 2019.The area of Sesuvium was counted from 2015 and reached 227.11 ha in 2019.

\subsection{Distribution changes of salt marshes in different provinces}

Intertidal salt marshes of China are too long from north to south, and salt marshes in different places showed various erosion and expansion patterns and dynamics. We choose three typical provinces for discussion.

\subsubsection{Shandong Province}

The salt marshes of Shandong province are Suaeda, Phragmites, Spartina and Tamarix. Since the introduction of Spartina in 1990, the area of Spartina in Shandong increased exponentially. It increased from 128.38 ha in 1990 to 6980.76 ha in 2019. Spartina occupies the niche of local salt marshes and dispersals rapidly (average dispersal rate is $236.29 \mathrm{ha} / \mathrm{a}$ ). The largest Spartina distribution area is in the Yellow River Delta, which is the habitat of red-crowned cranes, black-headed gulls and other rare waterfowl. If Spartina continues to expand at this rate, the ecological balance of this area will be affected.

The overall trend of the area change of Phragmites - Tamarix in Shandong Province was to decrease to a stable state at first. The area of Phragmites - Tamarix reached 43941.79 ha in 1985 and decreased to 11291.24 ha in 1995, which was mainly due to a large amount of reclamation in the Yellow River Delta, which artificially enclosed the original growing area of Phragmites - Tamarix and cut off the contact with the natural intertidal zone. The steady state of Phragmites - Tamarix area from 1995 to 2019 is due to the fact that the intertidal area caused by sedimentation of estuarine delta and the reduced intertidal area caused by reclamation are in equal state on the whole.

Salaed $a$ as the main species of salt marshes in northern China, is widely distributed in Shandong province. The main distribution area of Salaeda in Shandong province is 
the Yellow River Delta, and there are scattered distribution in other areas of the province. The ecological niche of Suaeda was located at the forefront of the seaward side of the intertidal zone. A large amount of land was deposited in the Yellow River Delta in 19951995 , and the area of Suaeda also expanded rapidly during this period, and reached the maximum value of $60,881.06$ ha in 1990. In 1995, it gradually decreased with the expansion of Spartina. In addition, environmental pollution in Bohai Sea was also the factor that caused the area decrease of Suaeda in recent years.

\subsubsection{Jiangsu Province}

The total area of salt marshes in Jiangsu Province showed a decreasing trend from 1990 to 2010, and tended to be stable in recent years. The main reason for the decline of salt marshes is the reclamation of coastal land for fish ponds and farmland, which in recent years began to be converted from reclaimed land to construction land.

In 1985, Suaeda was the main salt marshes in Jiangsu Province, accounting for $85.85 \%$ of the total salt marshes area at that time. Since 1985, the area of Suaeda has been decreasing due to the push of Phragmites to the sea side to compete for the ecological niche of Suaeda. Since 2000, with the continuous expansion of Spartina area, Spartina was promoted to the land side instead of the sea side, which occupied the ecological niche of Suaeda and further reduced the area of Suaeda.

The competition between Spartina and Suaeda was obvious along the coast of Yancheng. The competition between Spartina and Suaeda changed from zero to three to three, and finally to two. The population changes were from the competition between Phragmites and Suaeda in 1985, to the coexistence of the competition between Phragmites and Suaeda and Spartina in 2000, to the co-competition between Phragmites and Spartina in 2010, and finally to the competition between Phragmites and Spartina in 2015.

\subsubsection{Shanghai City}

In the area of Yangtze River Deltas, the salt marshes are mainly dominated by Spartina, Scirpus and Phragmites. In Shanghai, Spartina showed an increasing trend from 1995 to 2019. The area of Spartina increased the fastest from 2010 to 2019, reaching $1601.37 \mathrm{ha} / \mathrm{a}$, and the total area of Spartina reached 16227.50 ha in 2019.Mainly distributed in Jinshan District, Fengxian District, Pudong New Area outside the Nanhui dike, Chongming Island, Changxing Island and other areas. The distribution characteristics are as follows: Scirpus is dominant in low tide level, Spartina is dominant in intertidal zone, and Phragmites is dominant in high tide level which is less affected by tide.

During 1985-1990, the area of Phragmites decreased slightly because the tidal flat area of Xinqiao Village in Chongming was gradually transformed into agricultural land, which made the area of Phragmites decreased. From 1990 to 1995, the expansion of Phragmites in the east beach of Chongming increased the area of Phragmites, which reached a maximum of $13,215.45$ ha in 1995 . The area of Phragmites decreased from 1995 to 2005 because of the decrease of the tidal flat area in Chongming East Beach. From 2005 to 2019, the Hengsha island and its surrounding areas were silted into a large area of land, which made the vegetation area of the salt marshes continuously expand. Because Spartina has a strong ability to promote silting and in turn strengthens the silting of the tidal flats, the tidal flats also continuously expand.

Scirpus as a local salt marshes species in Shanghai, was widely distributed in the east beach of Chongming, and the area of Scirpus reached 9145.20 ha in 1985. 
Scirpus, a pioneer species growing in the intertidal zone, was affected by the tidal flat area change and Spartina invasion from 1985 to 2019. In 2005, due to the large-scale reclamation in the east beach of Chongming, the area of shoal decreased, and the area of Scirpus reached the lowest point (only $3176.41 \mathrm{ha}$ ). Later, the shoal developed into a new light beach, which increased the area of salt marshes.

\section{Discussion}

5.1 Reliability and uncertainty of salt marshes mapping using Sentinel-2, Landsat data and GEE

In this study we demonstrated the reliability and feasibility of developing annual maps of salt marshes at $10-\mathrm{m}, 15-\mathrm{m}$ and $30-\mathrm{m}$ spatial resolution in Chinese intertidal zone using the Sentinel-2, Landsat TM/OLI images and the GEE cloud computing platform. Thanks to the open access Landsat data, GEE cloud computing platform and Arc GIS V10.4.1, we conducted this study successfully with high classification accuracy $(\mathrm{OA}>85 \%)$

Other researchers had completed the Spartina classification of the China using Landsat imageries in 2007 and 2014 to 2016 (Zuo, et al., 2012; Liu, et al., 2018). One of the reasons for the difference is that they selected study area is coastal zone, where the salt marshes's area is more grate than intertidal zone. The intertidal zone is more sensitive and have high productivity and biodiversity. We used all the available images within this study period in intertidal zone. Image data and algorithms are two of the several factors that could affect the accuracy of intertidal zone salt marshes mapping (Wang et al., 2020). The quality and the inconsistent availability of input images at various temporal and spatial scales has posed significant challenges to land cover mapping (Gong et al., 2013; Hansen et al., 2000). Utilizing a sun-synchronous satellite such asSentinel-2 and Landsat, it is inevitable that the sensor will only observe a portion of the full tidal range at any location, with less frequent observations at the extremely low and hightides (Dhanjal-Adams et al., 2016; Sagar et al., 2017). In addition, mNDWI plus AEWlsh were used to detect pure vegetation, pure tidal flat, and pure water in the study so that mixed pixels.

\subsection{Distribution of salt marshes along the China's coast in 1985-2019}

Of the about 1417000 acres of salt marshes distributed along the Chinese coast, mainly located around the Bohai Sea, Yellow Sea coasts, Yangtze River delta and Hangzhou Bay. The about 175000 acres of land reclaimed from salt marshes exceed the present whole area of China's vegetable tidal flats (Yang and Chen, 1994). At present, the relatively complete salt marshes only exists in the natural protection zone of Liao River estuary, Yellow Sea estuary and Yangtze River estuary. Salt marshes in different places showed various erosion and expansion patterns and dynamics, which demonstrated its distribution from Liaoning Province to Guangxi Province. The distribution of salt marshes is generally replaced by mangroves in areas with high temperature, which presents an overall situation of "more north and less south". With striking plant zonation patterns across steep environmental gradients, coastal salt marshes have been considered as ideal systems to investigate mechanisms of species distribution in natural habitats (He et al., 2010). Several natural and anthropogenic factors have had large influences on salt marshes distribution and dynamics in the intertidal zone.

Human activities were identified as the major driving factors that influence salt marshes in China. It's directly or indirectly affect the distribution and diffusion of salt marshes, mainly for prevention and control of human intervention and infrastructure 
to take up and reclamation of Spartina governance caused by salt marshes area change, like the Liao River delta, along the Yellow River delta, Jiangsu Province, Shanghai City and Hangzhou Bay region of salt marshes are affected by the serious artificial construction and land reclamation. Tidal flats were converted into aquatic farms and salt pans for economic benefits (Pan and Mei, 2017), during which salt marshes area declined rapidly. In addition, with the economic development and urbanization, coastal reclamation infrastructure activities have been continuously strengthened. During the five five-year "plan periods" from 1985 to 2010, the reclamation area of coastal wetlands on the mainland of China was $755,186 \mathrm{hm}^{2}$. After 2000, the reclamation intensity further increased and the reclamation area increased significantly (Wu et al., 2016). In the early 1990s, Shanghai municipal government began to introduce Spartina in order to promote silting and land formation. In 2001, the water conservancy department reintroduced Spartina alterniflora artificially in Scirpus and Guangtan in some areas of Dongtan of Chongming (Lin et al., 2015; Han et al., 2009; Li et al., 2006; Liu et al., 2013; Lu et al., 2013; Shen et al., 2006; Zou et al., 2014), since then, Spartina has spread further in other areas of Shanghai. And the comprehensive control project for Spartina was carried out in Chongming Island in 2012. A large area of Spartina was cut and Phragmites were planted on the bare lands after 2013. At the same time, human activities, such as shipping, fishing, sea driving and tourism, will increase the possibility of seed dispersal in salt marshes, which will lead to the dispersal. For example, in recent years, a large number of Spartina invasion was found in Tianjin Port and Weifang Port, and Scirpus was found in Shupaisha, Wenzhou City, Zhejiang Province. Environmental pollution from industrial production and oil exploration can also have an impact on salt marshes. The Liao River Delta and the Yellow River Delta are rich in petroleum resources. The industrial pollution produced in the process of petroleum exploitation and processing has a serious impact on the local Suaeda, Phragmites and so on. But, the main purpose of Spartina introduced in Shandong is to degrade pollution, promote silting and beautify the environment. The strong function of Spartina to promote silting and land formation has provided a large area of tidal flats in Haiyang City, Yantai City, which has been developed into shrimp ponds.

The combination of precipitation and temperature conditions affects the growth and distribution of salt marshes. Under the influence of temperate continental monsoon climate, the northern coastal areas of China are characterized by cold winter, sea ice below $0^{\circ} \mathrm{C}$, and hot and rainy seasons. In spring, they are relatively dry with less precipitation. Therefore, they are suitable for the growth of cold-resistant and drought-resistant plants such as Suaeda and Phragmites. Meanwhile, the germination of salt marshes seeds is directly affected, and sexual reproduction is inhibited. In the southern subtropical and tropical regions, there were abundant rainfall in winter and plum rain season, which were suitable for the growth of Scirpus, Cyperus, Sesuvium and Spartina; the seed germination rate was high, and the seed expansion was rapid through sexual reproduction. Coastal temperature in central China is warm and humid. Compared with light and humid conditions in the southern coast, the coastal areas of Jiangsu, Shanghai and Zhejiang are more conducive to Spartina growth and seed maturation. Due to the suitable hydrology, climate and soil conditions created a good environment and conditions for the settlement and diffusion of Spartina, and the total area of salt marshes in China increased from 93,257.97 ha in 2005 to 102,539.04 ha in 2010. In recent years, due to the global temperature rise and uneven inter-annual precipitation, the reduction of water resources in rivers in northern China has limited the growth of salt marshes. At the same time, due to the rising temperature, the 
salinity of sea water in some areas has also increased, affecting the growth of plants with weak salt tolerance, such as reed. Spartina has been expanding continuously in China due to the growing conditions and climate near suitable along the coast of China and the west coast of Atlantic Ocean where Spartina alterniflora steppe is produced.

Estuaries and mudflats have great influence on the distribution of salt marshes plants. Here we collected the sediment loads data from the Lijin Station (Pan and Mei, 2017) in the Yellow River Delta and the Datong Station (Wei et al., 2015) in the Yangtze River Delta to analyze the effect of tidal flat area change on salt marshes growth in China. At the Lijin Station, sediment load was high during 1986-2003 but started to decline linearly in 2004. At the Datong Station, sediment load was also high with a large interannual variation during 1985-2010 but had declined linearly since 2001. Salt marshes area dynamics in the coastal zone were affected by both sediment load from rivers (expansion) and erosion to the oceans (loss), which makes the length of shoreline increase continuously, and the land area gradually decreases after 2006 (Pan and Mei, 2017). The mudflat provides nutrients and space for seed colonization, germination, growth and diffusion of salt marshes. Estuaries are usually tidal, and the movement of waves helps seed dispersal, while the flattening of bays and silting of estuaries provide conditions for salt marshes to survive. The Yellow River carries a myriad of sediment to deposit here, which can annually create $1334-2001$ ha area of land on average (He et al., 2010). Spartina is distributed on both sides of the low tidal flat at the estuary of Yellow River, while the high tide beach is dominated by Phragmites and mixed with Tamarix. The river network in the coastal and southern areas of Jiangsu Province is densely distributed, with numerous rivers flowing into the sea. The coastline of Fujian and Zhejiang is tortuous, and the harbour is widely distributed. The coastal matrix of mainland China can be divided into sandy coast, silty coast, cornerstone coast and biological coast. Taking Hangzhou Bay as the boundary, most of the north coast except Shandong Peninsula and Liaodong Peninsula belongs to silt coast, and most of the south coast is bedrock coast. The biological coasts along the coastline of mainland China are mainly mangrove coasts distributed in the coastal areas south of Wenzhou.

The depth and salinity of sea water have great influence on the growth of salt marshes. In general, the subtidal zone was dominated by Suaeda, and Scirpus, etc., the mid-tidal zone was dominated by Spartina, Cyperus, and Sesuvium, etc., and the supratidal zone was dominated by Phragmites, Aeluropus, Tamarisk, and so on. This is mainly related to the tolerance of salt marshes plants to water inundation, salt tolerance, tidal invasion rate and hypoxia resistance. Due to Spartina had certain salttolerance, $10 \%$ to $20 \%$ was its optimal growth salinity, and its salt-tolerance strength was stronger than the local marshes plants such as Phragmites, Cyperus and Sesuvium were changed, but with the decrease of salinity, other vegetation and Spartina were in fierce competition, and the dominance of Spartina was not obvious, thus affecting its distribution. Some plants are under water for a long period of time, resulting in hypoxia of the root system, inhibiting photosynthesis and respiration, and eventually resulting in the death of salt marshes plants (Landin, 1991;Liu Mingyue, 2018).

\subsection{Future development}

Bayesian maximum entropy (BME) has exhibited powerful ability in dealing with remote sensing data by absorbing the spatial, temporal or spatiotemporal characteristics of the studied attribute, leading to more precise and less uncertainty outputs (Christakos, 1990, 2017; He and Kolovos, 2018). Therefore, it is worthy to 
explore the performance of SVM/BME combinations in identifying and classifying salt marshes in intertidal zone, like the synthesis methodology used in (He et al., 2020). Further, information entropy theory is a useful tool to quantify the richness of information provided by a map, and the Simpson index can be used to quantify the bio-diversity (Shannon, 1948; He et al., 2019; Wu et al., 2021); thus, future work can focus on digging deeper from the obtained space-time distribution maps and get more bio-information for further studying the human's impacts on the area or bio-diversity of the salt marshes.

\section{Conclusions}

Previous salt marshes classifications generally treated Spartina as single salt marshes type. Our data and knowledge of the spatio-temporal dynamics of salt marshes at large scales have been very limited. Open-access time series Landsat and Sentinel data, and the GEE cloud computing platform enable researchers to track the annual changes of salt marshes in China at 30-m and 15-m spatial resolution. Remote sensing methods were essential for understanding how these protected salt marshes changed from 1985 to 2019 . This analysis was contingent on the proliferation of remote sensing data which allowed for the synthesis of multiple data types to better understand salt marshes trends and dynamics.

This study used remote sensing data and techniques to assess the interannual variation of salt marshes on a large scale for the first time in China. The Landsat and Sentinel based time series vegetation indices and water-related spectral index captured the salt marshes with a small number of training datasets and achieved high accuracy. The quality and the inconsistent availability of Landsat images at temporal and spatial scales, along with our algorithms, could have introduced some uncertainty in our tidal flat maps. Other sensors (e.g., Worldview 3) with higher spatial and temporal resolution are becoming available, which will further help improve salt marshes mapping in the future. The results of this study can provide data reference for China's statistics of 'Blue Carbon' and provide scientific support for China to achieve the goal of 'carbon neutrality'.

\section{Acknowledgments}

This study was supported by the China Postdoctoral Science Foundation (2020M681825). The authors would like to thank the editors and anonymous reviewers for their insightful comments and suggestions.

\section{References}

Chung-Hsin Chung. 2005. Forty years of ecological engineering with Spartina plantations in China. Ecological Engineering 27, 49-57.

Chapman, V.J., Chadwick, M.J., 1974. Salt marshes and salt deserts of the world. Journal of Ecology 79(13), 3-19.

Zedler, J.B.; Kercher, S. 2005. Wetland resources: Status, trends, ecosystem services, and restorability. Annual Review of Environment \& Resources 30, 39-74.

Barbier, E.B., Hacker, S.D., Kennedy, C., Koch, E.W., Stier, A.C., Silliman, B.R., 2011. The Value of Estuarine and Coastal Ecosystem Services. Ecological Monographs 81(2), 169-193.

Crosby, S.C., Sax, D.F., Palmer, M.E., Booth, H.S., Deegan, L.A., Bertness, M.D., Leslie, H.M., 2016. Salt Marsh Persistence is Threatened by Predicted Sea-Level Rise. Estuarine Coastal \& Shelf Science 181, 93-99.

Watson, E.B., Raposa, K.B., Carey, J.C., Wigand, C., Warren, R.S., 2017. Anthropocene Survival of Southern New England's Salt Marshes. Estuaries Coasts 40, 617-625. 
Wigand, C., Roman, C.T., Davey, E., Stolt, M., Johnson, R., Hanson, A., Watson, E.B., Moran, S.B., Cahoon, D.R., Lynch, J.C., 2014. Below the Disappearing Marshes of an Urban Estuary: Historic Nitrogen Trends and Soil Structure. Ecological Applications 24, 633-649.

Altieri, A.H., Bertness, M.D., Coverdale, T.C., Herrmann, N.C., Angelini, C., 2012. A Trophic Cascade Triggers Collapse of a Salt-marsh Ecosystem with Intensive Recreational Fishing. Ecology 93, 1402-1410.

Deegan, L.A., Johnson, D.S., Warren, R.S., Peterson, B.J., Fleeger, J.W., Fagherazzi, S., Wollheim, W.M., 2012. Coastal Eutrophication as a Driver of Salt Marsh Loss. Nature 490, 388-392.

Kirwan, M.L., Guntenspergen, G.R., 2010. Influence of Tidal Range on the Stability of Coastal Marshland. Journal of Geophysical Research Earth Surface 115.

Kirwan, M.L., Murray, A.B., Boyd, W.S., 2008. Temporary Vegetation Disturbance as an Explanation for Permanent Loss of Tidal Wetlands. Geophysical Research Letters 35.

Holdredge, C., Bertness, M.D., Altieri, A.H., 2008. Role of Crab Herbivory in Die-O of New England Salt Marshes. Conservation Biology 23(3), 672-679.

Saintilan N, Wilson N.C, Rogers K, Rajkaran A, Krauss K.W., 2014. Mangrove expansion and salt marsh decline at mangrove poleward limits. Global Change Biol 20: 147-157.

Armitage A.R, Highfield W.E, Brody S.D, Louchouarn P., 2015. The contribution of mangrove expansion to salt marsh loss on the Texas Gulf Coast. PloS one 10: e0125404.

Chen, C, Borges, A., 2009. Reconciling opposing views on carbon cycling in the coastal ocean: Continental shelves as sinks and near-shore ecosystems as sources of atmospheric CO2. Deep-sea Reserch Part II-Topical Studies in Oceanography 56, (8-10),578-590.

Walsh, J.J., 1988. On the Nature of Continental Shelves. Academic Press, New York.

Walsh, J.J., 1991. Importance of continental margins in the marine biogeochemical cycling of carbon and nitrogen. Nature 350, 53-55.

Mackenzie, F.T., Lerman, A., Ver, L.M.B., 1998a. Role of continental margin in the global carbon balance during the past three centuries. Geology 26, 423-426.

Mackenzie, F.T., Ver, L.M.B., Lerman, A., 1998b. Coupled biogeochemical cycles of carbon, nitrogen, phosphorous and sulfur in the land-ocean-atmosphere system. In: Galloway, J.N., Melillo, J.M. (Eds.), Asian Change in the Context of Global Climate Change. Cambridge University Press, Cambridge, pp. 42-100.

Wollast, R., 1998. Evaluation and comparison of the global carbon cycle in the coastal zone and in the open ocean. In: Brink, K.H., Robinson, A.R. (Eds.), The Global Coastal Ocean. Wiley, New York, pp. 213-252.

Liu, K.K., Atkinsion, L., Chen, C.T.A., Gao, S., Hall, J., MacDonald, R.W., Talaue-McManus, L., Quinones, R., 2000. Exploring continental margin carbon fluxes on a global scale. EOS 81, 641-642 plus 644.

Muller-Karger, F.E., Varela, R., Thunell, R., Luerssen, R., Hu, C., Walsh, J.J., 2005. The importance of continental margins in the global carbon cycle. Geophysical Research Letters 32, L01602.

Brockmann, C., Stelzer, K., 2008. Optical remote sensing of intertidal flats. In: Barale, V., Gade, M. (Eds.), Remote Sensing of the European Seas. Springer, Netherlands, pp. 117-128.

Galbraith, H., Jones, R., Park, R., Clough, J., Herrod-Julius, S., Harrington, B., Page, G., 2002.Global climate change and sea level rise: potential losses of intertidal habitat for shorebirds. Waterbirds 25, 173-183

Bell, P.S., Bird, C.O., Plater, A.J., 2016. A temporal waterline approach to mapping intertidal areas using X-band marine radar. Coastal Engineering. 107:84-101. http://dx.doi.org/10.1016/j.coastaleng.2015.09.009.

Healy, T.R., Wang, Y., Healy, J.-A. (Eds.), 2002. Muddy Coasts of the World: Processes, Deposits, and Function. Gulf Professional Publishing.

Mason, D.C., Scott, T.R., Dance, S.L., 2010. Remote sensing of intertidal morphologicalchange in Morecambe Bay, U.K., between 1991 and 2007. Estuarine Coastal \& Shelf Science 87:487-496.

Brusati, E.D., Grosholza, E.D., 2007. Effect of native and invasive cordgrass on Macomapetalum density, growth, 
and isotopic signatures. Estuarine Coastal \& Shelf Science 71, 517-522.

Callaway, J.C., Josselyn, M.N., 1992. The introduction and spread of smooth cordgrass (Spartina alterniflora) in south San Francisco Bay. Estuaries 15, 218-226.

Daehler, C.C., Strong, D.R., 1996. Status, prediction and prevention of introduced cordgrass Spartina spp. invasions in Pacific estuaries, USA. Biological Conservation 78, 51-58.

Chen, Z.Y., Li, B., Chen, J.K., 2005. Some growth characteristics and relative compet-itive ability of invasive Spartina alterniflora and native Scirpus mariqueter. Chinese Biodivers 13 (2), 130-136 (in Chinese).

Rosso, P.H., Ustin, S.L., Hastings, A., 2006. Use of lidar to study changes associated with Spartina invasion in San Francisco Bay marshes. Remote Sensing of Environment. 100, 295-306.

Wang, A.J., Gao, S., Jia, J.J., 2006. Impact of S. Alterniflora on sedimentary and mor-phological evolution of tidal salt marshes in Jiangsu, China. Acta Oceanol. Sinica 28 (1), 92-99 (in Chinese).

He, W.S., Feagin, R., Lu, J.J., Liu, W.L., Yan, Q., Xie, Z.F., 2007. Impacts of intro-duced Spartina alterniflora along an elevation gradient at the Jiuduansha Shoals in the Yangtze Estuary, suburban Shanghai, China. Ecological Engineering 29, 245-248.

Huang, H.M., Zhang, L.Q., 2007. A study of the population dynamics of Spartina alterniflora at Jiuduansha shoals, Shanghai, China. Ecological Engineering 29, 164-172.

Li, H.P., Zhang, L.Q., 2008. An experimental study on physical controls of an exotic plant Spartina alterniflora in Shanghai, China. Ecological Engineering 32, 11-21.

Thomas, M.B., Reid, A.M., 2007. Are exotic natural enemies an effective way of controlling invasive plants? Trends in Ecology \& Evolution 22, 447-453.

Ayres, D.R., Klohr, S., Smith, D.L., Strong, D.R., Zaremba, K., 2004. Spread of exotic cordgrasses and hybrids (Spartina sp.) in the tidal marshes of San Francisco Bay, CA, USA. Biological Invasions 6, 221-231.

Zhang, R.S., Shen, Y.M., Lu, L.Y., Yan, S.G., Wang, Y.H., Li, J.L., Zhang, Z.L., 2004. Forma-tion of Spartina alterniflora salt marshes on the coast of Jiangsu Province, China. Ecological Engineering 23, 95-105.

Hinkle, R.L., Mitsch, W.J., 2005. Salt marsh vegetation recovery at salt hay farm wetland restoration sites on Delaware Bay. Ecological Engineering 25, 240-251.

Liu, M, Mao, D, Wang, Z., 2018. Rapid Invasion of Spartina alterniflora in the Coastal Zone of Mainland China: New Observations from Landsat OLI Images. Remote Sensing 10, 12.

Zuo, P., Zhao, S.H. , Liu, C.A., Wang, C.H., Liang, Y.B., 2012. Distribution of Spartina spp. along China's coast. Ecological Engineering 40. 160-166.

Wan, H.,Wang, Q., Jiang, D., Fu, J., Yang, Y., Liu, X., 2014. Monitoring the invasion of Spartina alterniflora using very high resolution unmanned aerial vehicle imagery in Beihai, Guangxi (China). The Scientific World Journal 2014, 638296.

Ouyang, Z., Zhang, M., Xie, X., Shen, Q., Guo, H., Zhao, B., 2011. A comparison of pixel-based and objectoriented approaches to VHR imagery for mapping saltmarsh plants. Ecological Informatics 6, 136-146.

Yu, Q., Gong, P., Clinton, N., Biging, G., Kelly, M., Schirokauer, D., 2006. Object-based detailed vegetation classification with airborne high spatial resolution remote sensing imagery. Photogrammetric Engineering \& Remote Sensing 72, 799-811.

Wang, A., Chen, J., Jing, C., Ye, G.,Wu, J., Huang, Z., Zhou, C., 2015. Monitoring the invasion of Spartina alterniflora from 1993 to 2014 with Landsat TM and SPOT 6 Satellite Data in Yueqing Bay, China. PLoS one 10, $\mathrm{e} 0135538$.

Zhu, X.D., Meng, L.X., Zhang, Y.H., Weng, Q.H., Morris, J. 2019

Tidal and Meteorological Influences on the Growth of Invasive Spartina alterniflora: Evidence from UAV R emote Sensing. Remote Sensing 11, 10.

Hird J.N., DeLancey E.R., MHecDermid G.J., Kariyeva J., 2017. Google Earth Engine, Open-Access Satellite 
Data, and Machine Learning in Support of Large-Area Probabilistic Wetland Mapping. Remote Sensing 9: 1315.

Google Earth Engine Team, 2017. Google Earth Engine: A Planetary-Scale Platform for Earth Science Data and Analysis. http://earthengine.google.com

Vogelmann J.E., Gallant A.L., Shi H., Zhu Z., 2016. Perspectives on monitoring gradual change across the continuity of Landsat sensors using time-series data. Remote Sensing of Environment 185: 258-270.

Fu P., Weng Q., 2016. A time series analysis of urbanization induced land use and land cover change and its impact on land surface temperature with Landsat imagery. Remote Sensing of Environment 175: 205-214.

Pasquarella V.J., Holden C.E., Kaufman L., Woodcock C.E., 2016. From imagery to ecology: leveraging time series of all available Landsat observations to map and monitor ecosystem state and dynamics. Remote Sensing in Ecology and Conservation 2(3):152-70.

Mao, D.H, Liu, M.Y, Wang, Z.M, Li, L,Man, W.D, Jia, M.M, Zhang, Y.Z., 2019.

Rapid Invasion of Spartina Alterniflora in the Coastal Zone of Mainland China: Spatiotemporal Patterns and Human Prevention. Sensor 10.3390/s19102308

Campbell, A.; Wang, Y., 2020. Salt marsh monitoring along the mid-Atlantic coast by Google Earth Engine enabled time series. PLoS one $15,2$.

Mohammadi, M., Rashid, T. A., Karim, S. H. T., Aldalwie, A. H. M., Quan Thanh, T., Bidaki, M., Rahmani, A. M., Hosseinzadeh, M., 2021. A comprehensive survey and taxonomy of the SVM-based intrusion detection systems. Journal of Network and Computer Applications 178.

Tucker, C.J., 1979. Red and photographic infrared linear combinations for monitoring vegetation. Remote Sensing of Environment 8, 127-150.

Huete, A.R., Liu, H.Q., Batchily, K., van Leeuwen, W. 1997. A comparison of vegetation indices over a global set of TM images for EOS-MODIS. Remote Sensing of Environment 59, 440-451.

Huete, A., Didan, K., Miura, T., Rodriguez, E.P., Gao, X., Ferreira, L.G. 2002. Overview of the radiometric and biophysical performance of the MODIS vegetation indices. Remote Sensing of Environment 83, 195-213.

S. K. McFEETERS. 1996. The use of the Normalized Difference Water Index (NDWI) in the delineation of open water features. International Journal of Remote Sensing 17(7): 1425.1432.

Chen, B.Q., Xiao, X.M., Li, X.P., Pan, L.H., Doughty, R., Ma, J., Dong, J.W., Qin, Y.W., Zhao, B., Wu, Z.X., Sun, R., Lan, G.Y., Xie, G.S., Clinton, N., Giri, C. 2017. A mangrove forest map of China in 2015: analysis of time series Landsat 7/8 and Sentinel-1A imagery in Google Earth Engine cloud computing platform. ISPRS J. Photogramm. Remote Sensing 131, 104-120.

$\mathrm{Xu}, \mathrm{H}$. 2006. Modification of normalised difference water index (NDWI) to enhanceopen water features in remotely sensed imagery. International Journal of Remote Sensing 27, 3025-3033.

Feyisa, G.L., Meilby, H., Fensholt, R., Proud, S.R., 2014. Automated water extraction index: A new technique for surface water mapping using Landsat imagery. Remote Sensing of Environment 140. 23-35.

Yang S.L., Chen Y.J., 1994. Coastal salt marshes and mangrove swamps in china. Chin. J. Oceanol. Limnol. 13. 4. Wang, X.X., Xiao, X.M., Zou, Z.H., Chen, B.Q., Ma, J., Dong, J.W., Doughty, R.B., Zhong, Q.Y., Qin, Y.W., Dai, S.Q., Li, X.P., Zhao, B., Li, B., 2020. Tracking annual changes of coastal tidal flats in China during 1986 2016 through analyses of Landsat images with Google Earth Engine. Remote Sensing of Environment 238.

Gong, P., Wang, J., Yu, L., Zhao, Y.C., Zhao, Y.Y., Liang, L., Niu, Z.G., Huang, X.M., Fu, H.H., Liu, S., Li, C.C., Li, X.Y., Fu, W., Liu, C.X., Xu, Y., Wang, X.Y., Cheng, Q., Hu,L.Y., Yao, W.B., Zhang, H., Zhu, P., Zhao, Z.Y., Zhang, H.Y., Zheng, Y.M., Ji, L.Y.,Zhang, Y.W., Chen, H., Yan, A., Guo, J.H., Yu, L., Wang, L., Liu, X.J., Shi, T.T., Zhu, M.H., Chen, Y.L., Yang, G.W., Tang, P., Xu, B., Giri, C., Clinton, N., Zhu, Z.L., Chen, J.,Chen, J., 2013. Finer resolution observation and monitoring of global land cover: firstmapping results with Landsat TM and ETM+ data. International Journal of Remote Sensing 34,2607-2654. 
Hansen, M.C., Defries, R.S., Townshend, J.R.G., Sohlberg, R., 2000. Global land coverclassification at $1 \mathrm{~km}$ spatial resolution using a classification tree approach. International Journal of Remote Sensing 21, 13311364.

Dhanjal-Adams, K.L., Hanson, J.O., Murray, N.J., Phinn, S.R., Wingate, V.R., Mustin, K.,Lee, J.R., Allan, J.R., Cappadonna, J.L., Studds, C.E., Clemens, R.S., Roelfsema, C.M.,Fuller, R.A., 2016. The distribution and protection of intertidal habitats in Australia. Етu 116 (208).

Sagar, S., Roberts, D., Bala, B., Lymburner, L., 2017. Extracting the intertidal extent and topography of the Australian coastline from a 28 year time series of Landsat observations. Remote Sensing of Environment 195, 153-169.

Wang, J., Zhang, H.B., Liu, Y.Q., Han, S., Xu, Y., Zhang, Y.N., 2020. Interspecific pattern and competitive relationship of plant community in Yancheng coastal wetland. Acta Ecologica Sinica 40(24).

He Q., An Y., Cui B.S. 2010. Ecology and Environmental Sciences,19(03):657-664.

Lin, W., Chen, G. , Guo, P., Zhu, W., Zhang, D.H., 2015. Remote-sensed monitoring of dominant plant species distribution and dynamics at Jiuduansha Wetland in Shanghai, China. Remote Sensing 7(8): 10227-10241.

Han, Z., Liu, Y., Yun, C.X., Zheng, J.H., 2009. Spatial and temporal dynamics of vegetation communities in the eastern beach of Chongming based on remote sensing and GIS technology. Ocean Engineering Branch of the Chinese Society of Oceanography: Ocean Engineering Branch of the Chinese Society of Oceanography 5.

Li, H.P., Zhang, L.Q., Wang, D.H. 2006. Distribution status of alien Spartina alterniflora species in Shanghai. Biodiversity Science 14(2): 114-120.

Liu, Y., Li, X.Z., Yan, Z.Z., Chen, X.Z., He, Y.L., Guo, W.Y., Sun, P.Y., 2013. Biomass and carbon storage of reed and Spartina alterniflora in Jiuduansha salt marsh of Yangtze River estuary. Chinese Journal of Applied Ecology 24(08):2129-2134.

Lu, Y.Y., Li, D.Z., Xu, J., Xu, L.L., Gao, J.J., Pan, Y., Zhao, M.X., Cheng, L.L., Wang, H., He, Y.Y., 2013. Spatial and temporal dynamics of non-structural carbohydrate content in Phrzeolus communis and Spartina alterniflora in Chongming East Beach wetland. Journal of Northeast Forestry University 41(3): 85-89+121.

Shen, F., Zhou, Y.X., Zhang, J., Wu, J.P., Yang, S.L., 2006. Remote sensing monitoring and analysis of vegetation in Jiuduansha wetland. Oceanologia et Limnologia Sinica 37(6): 498-504.

Zou, Y.A., Niu, J.Y., Tang, C.D., Pei, E.L., Tang, S.X., Lu, S., Wang, T.H., 2014. Changes in suitable habitat of Charadriiform waterbirds along the East Asian-Australia migration route: A case study of the Chongming Dongdian migration site. Chinese Journal of Ecology 33(12): 3300-3307.

Pan, B., Mei, H., 2017. Study on the Influence of Water and Sediment in the Yellow River on the Delta Front. Shandong Normal University, Jinan, China.

Wei, W., Tang, Z., Dai, Z., Lin, Y., Ge, Z., Gao, J., 2015. Variations in tidal flats of the Changjiang (Yangtze) estuary during 1950s-2010s: future crisis and policy implication. Ocean \& Coastal Management 108, 89-96.

Christakos, G., 2017. Spatiotemporal random fields: theory and applications. Elsevier.

Christakos, G., 1990. A Bayesian Maximum-Entropy View to the Spatial Estimation Problem. Mathematical Geology 22, 763-777.

He, J., Chen, Y., Wu, J., Stow, D.A., George, C., 2020. Space-time chlorophyll-a retrieval in optically complex waters that accounts for remote sensing and modeling uncertainties and improves remote estimation accuracy. Water Research 171, 115403.

He, J., Christakos, G., Jankowski, P., 2019. Comparative Performance of the LUR, ANN, and BME Techniques in the Multiscale Spatiotemporal Mapping of PM 2.5 Concentrations in North China. IEEE J. Sel. Top. Appl. Earth Observations Remote Sensing 12, 1734-1747.

He, J., Kolovos, A., 2018. Bayesian maximum entropy approach and its applications: a review. Stoch Environ Res Risk Assess 32, 859-877. 
Shannon, C., 1948. A Mathematical Theory of Communication. Bell System Technical Journal 27, 623-656.

Wu, J., He, J., Christakos, G., 2021. Quantitative Analysis and Modeling of Earth and Environmental Data.

Elsevier. 